\title{
Performance Evaluation of Flexible Pavement Using Carbon Nanotubes and Plastic Waste as Admixtures
}

\author{
Aamir Ayaz KHAN, Inam Ullah KHAN, Malik Muneeb ABID*, Muhammad NOMAN, Umair Ayaz KHAN, Muhammad BILAL
}

\begin{abstract}
This paper investigates the properties of waste plastic film and carbon nanotubes modified asphalt mixes. The composed asphalt mixes have been evaluated for fatigue cracking and rutting. In this research, a total of 30 numbers of samples were prepared with different percentages of waste plastic films and carbon nanotubes from 0.1 to $0.4 \%$ and evaluated for dynamic stability and rutting using the wheel tracking machine. Results show that the addition of carbon nanotubes significantly increases the dynamic stability of asphalt and decreases the rutting up to a sufficient level as compared to plastic and conventional bitumen.
\end{abstract}

Keywords: bitumen; dynamic stability; nanotubes; rutting test; wheel tracking test

\section{INTRODUCTION}

Construction of road and highways is significant for the economic development of a country. Pakistan is lying in the center of South Asia; for better trading and a balance economy road links and networks are essential. A good transportation system provides an efficient means to carry different necessary products, agricultural and daily life necessities.

Pavement is a multilayer system which distributes the vehicular load over a larger area. There are mainly two types of pavements, rigid and flexible pavement. The main difference between these two pavements is that the upper surface of the rigid pavement is made of concrete and the upper surface of flexible pavement is made of asphalt. The flexible pavement distributes the loading stress to the soil (subgrade) in less magnitude on which the soil will not shear or distort, i.e., from 150 psi to 3 psi. The asphaltic binders behave as visco-elastic material; its behavior changes as temperature increases. This behavior is mainly dependent upon the temperature and loading as well. At a colder temperature, the asphaltic binder behaves as stiffer material, so the ambient temperature is the primary parameter in design. At very low temperature (less than $0{ }^{\circ} \mathrm{C}$ ) the asphaltic binder behaves as stiffer solid and deformed by applying to load. When the load is removed, it bounces back to its original shape. Asphaltic binder shows unique characteristics; when it is very hot temperature, it becomes soft, at a temperature above $1000{ }^{\circ} \mathrm{C}$, it becomes very soft, and behaves like viscous fluid on a very hot temperature. High test temperature simulates slow loading while low test temperature simulates high loading because for low loading it is stiffer while for long loading it is softer. At moderate temperature, it behaves like both [1].

Traffic loading and severe weather conditions are critical among the factors, which deteriorate the highways with the passage of time [2, 3]. A number of blends have been designed and analyzed by different researchers to enhance bitumen characteristics [4]. Recent studies showed that additives like sulfur [5], polyphosphoric acids [6], and fatty acid amides [7] could enhance the bitumen properties. Many researchers [8-11] have also employed polymers in asphalt mixes. It has been reported that Styrene-Butadiene-Styrene copolymer (SBS) and Styrene-Butadiene Rubber (SBR) are among the widely used polymers to attain the desirable properties of bitumen.
In addition, researchers $[8,12]$ have analyzed the addition of Ethylene Vinyl Acetate (EVA) and PolyEthylene (PE). It has been found that these modifiers can modify the basic properties of the bitumen. Moreover, the blending can reduce the construction cost [13]. Sustainability by managing limited natural resources is the primary objective of researchers around the World [14]. A variety of waste products has been used in asphalt pavement i.e., glass [9], crumbed rubber [15], and crushed waste bricks [16]. All these studies reported that recycled material could be a cost-effective substitute for the aggregates in the asphalt. Natural rubber and reclaimed geomembranes with polystyrene and polypropylene have also been utilized for desired properties in bitumen [17].

The deformation in the pavement is commonly determined by the Wheel Tracking machine test which gives us the values of dynamic stability and rutting [27]. In this research, we used two different materials (plastic waste and carbon nanotubes) with different percentages in the asphalt mix. Subsequently, their effects in terms of dynamic stability and rutting have been evaluated and compared.

\section{LITERATURE REVIEW}

It has been indicated by Tabakovic et al. [18] that for self-healing of asphalt pavements the best option is to use the nanoparticles. Hui Yao et al. [19] concluded that the use of silica increases the rheological properties of asphalt binder. Jahromi [20] observed that the addition of nanofiber has suitable effects on properties of bitumen mixtures by decreasing the flow value and increasing its stability and voids volume. As such, it can be expressed that the use of carbon nanofiber probably improves resistance properties to distress occurring in road pavement due to traffic loads. Santagata et al. [21] showed that CNTs provide an enhancement of rutting resistance potential and resistance to thermal cracking. Moreover, susceptibility to oxidative aging is reduced with further advantages that are expected in the long-term performance of bituminous mixtures. Moreover, CNT can be used to increase the rheological properties of asphalt binder after short and long-term aging treatments. Putman et al. [22] recommended the use of relatively high percentages of $\mathrm{CNF}(>1)$ to increase resistance against permanent deformation at high temperatures. Khattak et al. [23] concluded that the use of carbon nano-fiber modified 
asphalt may increase the resistance against rutting and fatigue. Another study by Hussain et al. [24] suggested that in order to achieve the carbon nanofibers/matrix modified bitumen adhesion it is necessary to have the full potential of nano reinforced composite materials. Liu Xiaoming et al. [25] showed in their research that the use of CNT along with bitumen enhances the properties of pavement against fatigue and rutting. Zhu et al. [26] concluded that Polymer modified Bitumen (PMB) can be used as an anti-rutting agent in pavements. It has been concluded that the use of CNT modified binders in higher percentages improves its rheological characteristics.

\section{RESEARCH METHODOLOGY}

To find out the optimum plastic content to be used in Hot Mix Asphalt (HMA), we have conducted a comparative analysis of modified bitumen HMA and unmodified (conventional) HMA. Recently, Moghadaset al. [28] developed an experimental design/methodology for the effects of high-density polyethylene on fatigue and rutting.

Wheel tracking apparatus has been used to run a simulative test that measures the HMA qualities by rolling a small wheel device at a constant temperature of $60^{\circ} \mathrm{C}$ across a prepared HMA specimen and performance is then correlated to the actual HMA layer. It mainly gives the dynamic stability and rutting value at two different times, first at 45 minutes and second at 60 minutes. The wheel pressure is $0.7 \mathrm{MPa}$. The modulus of the sample is 0.1 , and the correction factor of the testing machine is 0.1 . Rutting is generally affected by the temperature and loading intensity. Wheel tracking machine allows asphalt to be tested for its ability to withstand repeated axial loading at varying temperatures [27].

Dynamic stability is an important property used in the mechanistic analysis of pavement response under moving loads as well as an input parameter for the design of flexible pavements. The dynamic stability and rutting tests have been conducted on the specimens using a repeatedload test setup in the Wheel tracking machine at $600{ }^{\circ} \mathrm{C}$ temperature. Half a sine-shaped wave load pulse was used to simulate the traffic wheel loading for 60 minutes load duration.

The maximum size and aggregate grading used were as per specifications of the National Highway Authority (NHA), Pakistan. Aggregate grading "Class-B" for wearing coarse has been used (Tab. 1).

Table 1 NHA gradation class-B aggregate

\begin{tabular}{|c|c|c|c|}
\hline \multicolumn{2}{|c|}{ Sieve Size } & \multicolumn{2}{c|}{$\begin{array}{c}\text { Combined grading (Asphalt Wearing } \\
\text { Course Class-B) }\end{array}$} \\
\hline inches & $\mathrm{mm}$ & $\begin{array}{c}\text { Gradation "B" } \\
\text { (Coarse Graded) }\end{array}$ & $\begin{array}{c}\text { NHA specifications } \\
\text { Class "B" }\end{array}$ \\
\hline 1 & 25 & - & - \\
\hline $3 / 4$ & 19 & 100 & 100 \\
\hline $1 / 2$ & 12.50 & 82.5 & $75-90$ \\
\hline $3 / 8$ & 9.50 & 70 & $60-80$ \\
\hline$\# 4$ & 4.75 & 50 & $40-60$ \\
\hline$\# 8$ & 2.36 & 30 & $20-40$ \\
\hline$\# 50$ & 0.300 & 10 & $5-15$ \\
\hline$\# 200$ & 0.075 & 5.5 & $3-8$ \\
\hline
\end{tabular}

The maximum size of aggregate is related to the typical lift thickness used on National Highways in Pakistan.
Details of the job mix design have been provided in Appendix A.

\subsection{Specification of the Wheel Tracking Test}

The temperature of the test is kept at $60^{\circ} \mathrm{C}$. Before the test, the specimen is kept for $6 \mathrm{hrs}$ at $60^{\circ} \mathrm{C}$. The wheel load is equal to $700 \mathrm{~N}$. The wheel completes its 42 cycles in one minute.

\subsection{Conventional Molds}

Conventional samples were made by mixing bitumen with aggregate after graduation. There is no addition of additives and almost 6 molds are prepared according to the following data as shown in Tab. 2. The Bitumen Content used is Optimum Binder Content and the bitumen used is $60 / 70$ grade.

Table 2 Mixing details of the conventional mold

\begin{tabular}{|c|c|c|}
\hline Methodology & \multicolumn{2}{|c|}{ (Bitumen + Aggregate) } \\
\hline No. of samples & Bitumen $/ \%$ & Aggregate / \% \\
\hline 3 & 4.8 & 95.2 \\
\hline
\end{tabular}

\subsection{By Using Plastic Waste}

First aggregates were mixed with bitumen at the temperature of $160{ }^{\circ} \mathrm{C}$ in Marshall Mixer and then waste plastic film is added in the percentage of $0.1 \%, 0.2 \%$, and $0.3 \%$ by weight (Tab. 3 ). The mixing has been conducted according to the following data. The Bitumen Content used is Optimum Binder Content and the bitumen used is 60/70 grade.

Table 3 Mixing details of molds by using waste plastic films in different percentages

\begin{tabular}{|c|c|c|c|}
\hline Methodology & \multicolumn{3}{|c|}{ (Bitumen + Aggregate) + Waste plastic films } \\
\hline No. of samples & Bitumen / \% & $\begin{array}{c}\text { Waste Plastic } \\
\text { Films / \% }\end{array}$ & Aggregate / \% \\
\hline 3 & 4.8 & 0.1 & 95.1 \\
\hline 3 & 4.8 & 0.2 & 95 \\
\hline 3 & 4.8 & 0.3 & 94.9 \\
\hline 3 & 4.8 & 0.4 & 94.8 \\
\hline
\end{tabular}

\subsection{By Using Carbon Nanotubes}

First aggregates were mixed with bitumen at high temperature and then carbon nanotubes were added in the percentage of $0.1 \%, 0.2 \%$, and $0.3 \%$ by weight as shown in Tab. 4. The Bitumen Content used is Optimum Binder Content and the bitumen used is 60/70 grade.

Table 4 Mixing details of molds by using carbon nanotubes in different percentages

\begin{tabular}{|c|c|c|c|}
\hline Methodology & \multicolumn{4}{|c|}{ (Bitumen + Aggregate) + Carbon Nano Tubes } \\
\hline No. of samples & Bitumen / \% & $\begin{array}{c}\text { Carbon Nano } \\
\text { Tubes / \% }\end{array}$ & Aggregate / \% \\
\hline 3 & 4.8 & 0.1 & 95.1 \\
\hline 3 & 4.8 & 0.2 & 95 \\
\hline 3 & 4.8 & 0.3 & 94.9 \\
\hline 3 & 4.8 & 0.4 & 94.8 \\
\hline
\end{tabular}

\section{RESULTS AND DISCUSSIONS}

The prepared samples were tested for dynamic stability and rutting in the wheel tracking machine; the following data was observed and collected. 


\subsection{Dynamic Stability}

Dynamic stability is a property of flexible pavement that shows resistance to rutting. The dynamic stability observed for conventional, waste plastic films and carbon nanotubes were as follows:

\subsubsection{Waste Plastic Films}

The first bitumen was mixed with aggregates in Marshall Mixer at $160{ }^{\circ} \mathrm{C}$. Subsequently, waste plastic films were added at percentages of $0.1 \%, 0.2 \%, 0.3 \%$, and $0.4 \%$ by weight. 12 samples were prepared, 3 for each percentage, and then these samples were tested in a wheel tracking machine. The following results of dynamic stability were observed as shown in Tab. 5. Dynamic stability increases with an increase in the percentage of plastic waste but up to $0.2 \%$ after that, the increase in the percentage of plastic waste decreases the dynamic stability, evidence also available from Rokade [29]. The reason behind this phenomenon is that the bond between bitumen and aggregates is the strongest bond and if we increase the percentage of plastic waste the bond becomes weak.

Table 5 Dynamic stability of plastic waste (used in asphalt)
\begin{tabular}{|c|c|c|c|c|c|}
\hline S. No. & $0 \%$ & $0.10 \%$ & $0.20 \%$ & $0.30 \%$ & $0.40 \%$ \\
\hline 1 & 1800 & 3000 & 7875 & 5250 & 4962 \\
\hline 2 & 1703 & 2739 & 7000 & 4846 & 4625 \\
\hline 3 & 1750 & 2625 & 7000 & 5250 & 4871 \\
\hline Avg. & 1751 & 2788 & 7292 & 5115 & 4819.33 \\
\hline
\end{tabular}

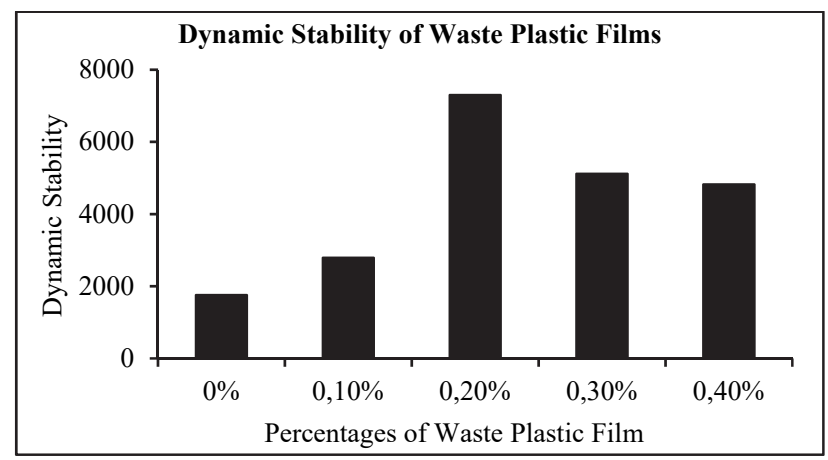

Figure1 Dynamic stability against varying percentages of waste plastic film

Fig. 1 shows that the dynamic stability in the case of waste plastic films increases with increase of the percentage of waste plastic films but up to $0.2 \%$ after that the increase of waste plastic films decreases the dynamic stability, evidence also available from Rokade [29]. Fig. 1 shows that dynamic stability in the case of waste plastic films is higher than conventional samples. If we use $0.2 \%$ waste plastic films it will give us higher dynamic stability as its beneficial reuse of plastic; the same can be seen in the study of Vasudevan et al. [30].

\subsubsection{Dynamic Stability of Carbon Nano Tubes}

First bitumen was mixed with aggregates in Marshall Mixer at $160{ }^{\circ} \mathrm{C}$. Subsequently, Carbon Nano Tubes are added at percentages of $0.1 \%, 0.2 \%, 0.3 \%$ and $0.4 \%$ by weight. 12 samples are prepared, 3 for each percentage and then these samples are tested in a wheel tracking machine. The following results of dynamic stability are observed as shown in Tab. 6. Dynamic stability increases with increasing the percentage of Carbon nanotubes. Arabani and Faramarzi [31] concluded the same, but up to $0.3 \%$ after that increase in the percentage of Carbon nanotubes decreases the dynamic stability. Because the bond between bitumen and aggregates is the strongest bond and if we increase the percentage of plastic waste the bond becomes weak. Agzenai et al. [32] presented that the carbon nanotubes may also do self-healing of asphalt.

Table 6 Dynamic stability of carbon nanotubes (used in asphalt)

\begin{tabular}{|c|c|c|c|c|c|}
\hline S. No. & $0 \%$ & $0.10 \%$ & $0.20 \%$ & $0.30 \%$ & $0.40 \%$ \\
\hline 1 & 1800 & 5250 & 5727 & 9000 & 7000 \\
\hline 2 & 1703 & 5250 & 7683 & 9000 & 7875 \\
\hline 3 & 1750 & 6300 & 7000 & 12600 & 6300 \\
\hline Avg. & 1751 & 5600 & 6803 & 10200 & 7058 \\
\hline
\end{tabular}

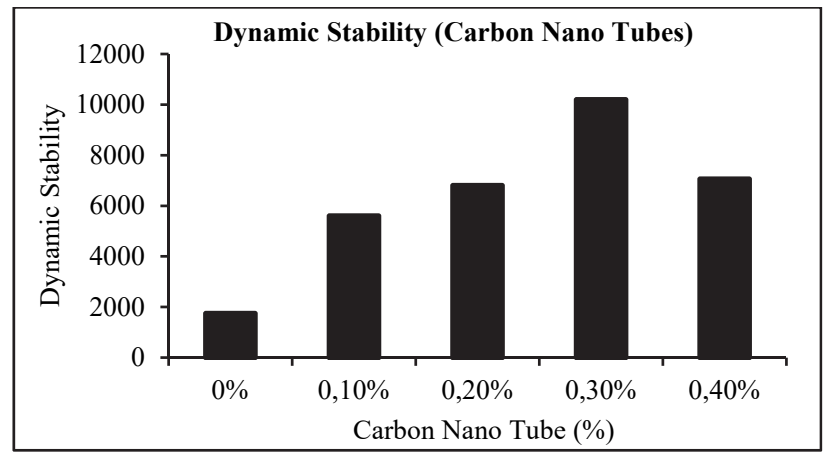

Figure 2 Dynamic stability against varying percentages of nano tubes

Fig. 2 shows that the dynamic stability in the case of plastic waste increases with an increase of carbon nanotubes but up to $0.3 \%$ after that increase the percentage of carbon nanotubes decreases the dynamic stability [33]. Moreover, it shows that dynamic stability in the case of Carbon Nano Tubes is higher than conventional samples.

\subsubsection{Comparison}

The comparison presented shows the values for the dynamic stability of conventional $(0 \%)$, waste plastic films and carbon nanotubes added in asphalt at different percentages. The following values are the highest values observed at different percentages.

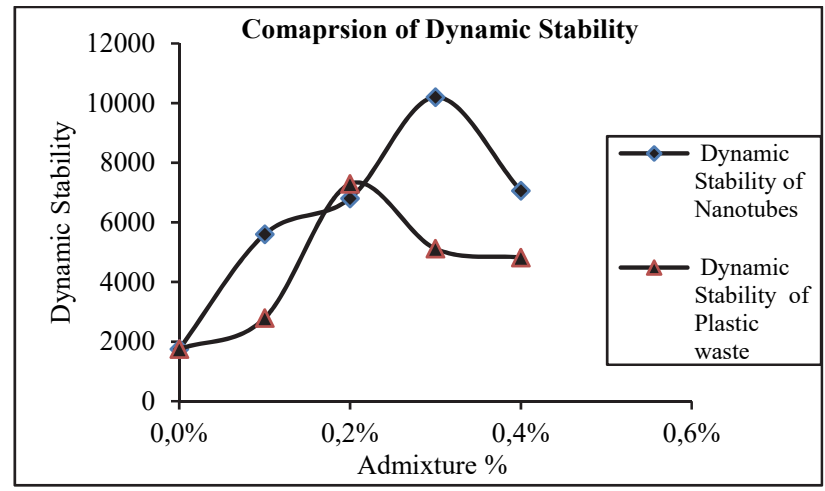

Figure 3 Dynamic stability of waste plastic film and carbon nanotubes against its varying percentage

Fig. 3 shows that the dynamic stability is higher at $0.3 \%$ carbon nanotubes as compared to $0.2 \%$ plastic waste with the conventional mix but if we compare the dynamic stability of plastic with the conventional mix then the dynamic stability in the case of waste plastic films is much 
higher as compared to conventional which shows that plastic is a good modifier and can be used in asphalt for decreasing the rutting. The use of plastic in asphalt for dynamic stability may decrease the cost of the project, and the environment as well will be sustainable by getting rid of these non-biodegradable materials.

\subsection{Rutting}

The deformation occurring due to heavy traffic along the wheel of vehicles is called rutting. The rutting values for the conventional, plastic waste and carbon nanotubes are as follows:

\subsubsection{Waste Plastic Films}

First bitumen is mixed with aggregates in the Marshall mixer at $160{ }^{\circ} \mathrm{C}$. Subsequently, waste plastic films are added at percentages of $0 \%$ (conventional) $0.1 \%, 0.2 \%$, and $0.3 \%$ by weight. 12 samples are prepared, 3 for each percentage and then these samples are tested in a wheel tracking machine. The following results of rutting values are observed, as shown in Tab. 7.

Rutting decreases with an increase in the percentage of waste plastic films but up to $0.2 \%$ after that increase in the percentage of waste plastic films decreases the rutting. Huang et al. [34] presented the same results.
$D 1$ is the deformation observed at 45 minutes and $D 2$ is deformation observed at 60 minutes.

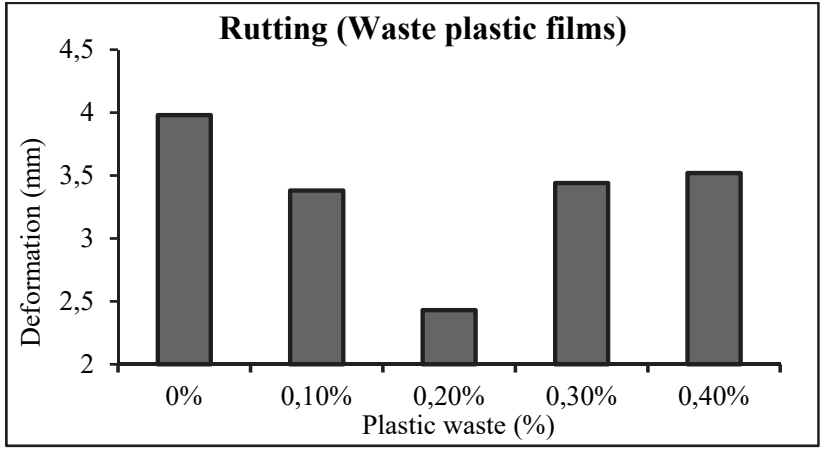

Figure 4 Rutting values of plastic waste against varying plastic percentage

Fig. 4 shows that the rutting value in the case of plastic waste decreases with an increase in the percentage of plastic but up to $0.2 \%$ after that the increase in the percentage of plastic waste increases the rutting value increases [35]. Moreover, it shows that rutting value in the case of plastic is lower than conventional samples.

If we use $0.2 \%$ plastic waste, it will give us lower values of rutting as its beneficial reuse of plastic.

Table 7 Rutting values of waste plastic films (used in asphalt)

\begin{tabular}{|c|c|c|c|c|c|c|c|c|c|c|}
\hline \multirow[t]{2}{*}{ S. No. } & \multicolumn{2}{|c|}{$0 \%$} & \multicolumn{2}{|c|}{$0.10 \%$} & \multicolumn{2}{|c|}{$0.20 \%$} & \multicolumn{2}{|c|}{$0.30 \%$} & \multicolumn{2}{|c|}{$0.40 \%$} \\
\hline & $D 1$ & $D 2$ & $D 1$ & $D 2$ & $D 1$ & D2 & $D 1$ & $D 2$ & $D 1$ & $D 2$ \\
\hline 1 & 3.89 & 4.24 & 3.22 & 3.43 & 2.42 & 2.5 & 3.32 & 3.44 & 3.51 & 3.65 \\
\hline 2 & 3.51 & 3.88 & 3.11 & 3.34 & 2.25 & 2.34 & 3.28 & 3.41 & 3.32 & 3.33 \\
\hline 3 & 3.45 & 3.81 & 3.12 & 3.36 & 2.37 & 2.46 & 3.35 & 3.47 & 3.5 & 3.59 \\
\hline Avg. & \multicolumn{2}{|c|}{3.98} & \multicolumn{2}{|c|}{3.38} & \multicolumn{2}{|c|}{2.43} & \multicolumn{2}{|c|}{3.44} & \multicolumn{2}{|c|}{3.52} \\
\hline
\end{tabular}

\subsubsection{Rutting Values of Carbon Nano Tubes}

First bitumen was mixed with aggregates in Marshal mixer at $160{ }^{\circ} \mathrm{C}$. Subsequently, carbon nanotubes are added at percentage of $0 \%$ ( conventional), $0.1 \%, 0.2 \%$, $0.3 \%$, and $0.4 \%$ by weight. 15 samples are prepared, 3 for each percentage and then these samples are tested in a wheel tracking machine.
The following results of rutting values are observed as shown in Tab. 8. Rutting decreases with an increase in the percentage of carbon nanotubes but up to $0.3 \%$ after that increase in the percentage of Carbon nanotubes, the rutting decreases [33].

$D 1$ is the deformation observed at 45 minutes and $D 2$ is deformation observed at 60 minutes.

Table 8 Rutting values of carbon nano tubes (used in asphalt)

\begin{tabular}{|c|c|c|c|c|c|c|c|c|c|c|}
\hline \multirow[t]{2}{*}{ S. No. } & \multicolumn{2}{|c|}{$0 \%$} & \multicolumn{2}{|c|}{$0.10 \%$} & \multicolumn{2}{|c|}{$0.20 \%$} & \multicolumn{2}{|c|}{$0.30 \%$} & \multicolumn{2}{|c|}{$0.40 \%$} \\
\hline & $D 1$ & D2 & $D 1$ & $D 2$ & $D 1$ & D2 & $D 1$ & D2 & $D 1$ & D2 \\
\hline 1 & 3.89 & 4.24 & 3.01 & 3.13 & 2.13 & 2.24 & 2.01 & 2.08 & 2.32 & 2.41 \\
\hline 2 & 3.51 & 3.88 & 3.12 & 3.24 & 2.33 & 2.412 & 1.45 & 1.52 & 2.24 & 2.32 \\
\hline 3 & 3.45 & 3.81 & 3.15 & 3.25 & 2.24 & 2.33 & 1.56 & 1.61 & 2.25 & 2.35 \\
\hline Avg. & \multicolumn{2}{|c|}{3.98} & \multicolumn{2}{|c|}{3.21} & \multicolumn{2}{|c|}{2.33} & \multicolumn{2}{|c|}{1.74} & \multicolumn{2}{|c|}{2.36} \\
\hline
\end{tabular}

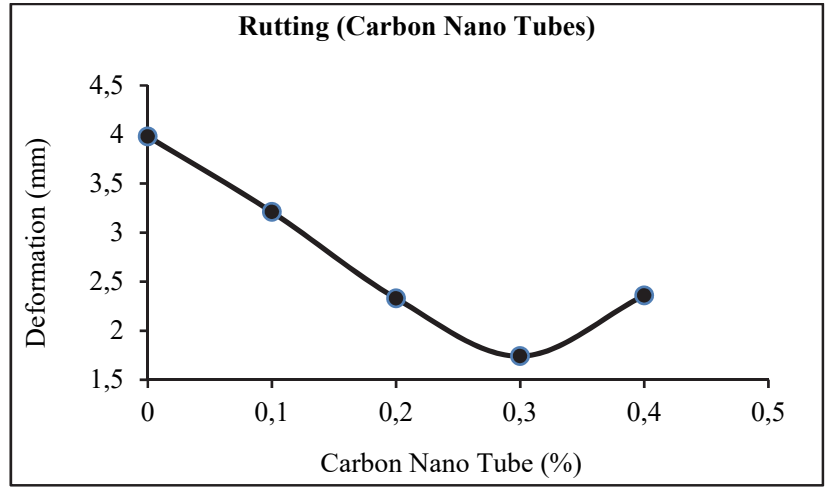

Figure 5 Rutting values of carbon nanotubes
Fig. 5 shows that the rutting value in the case of carbon nanotubes decreases when we increase the percentage of carbon nanotubes, but up to $0.3 \%$ after that increase the percentage of carbon nanotubes increases the rutting value increases [31]. Moreover, it shows that the rutting value in the case of carbon nanotubes is lower than in conventional samples.

\subsubsection{Comparison}

To find the apt mix, comparison has been conducted among the values for rutting of conventional $(0 \%)$, plastic waste and carbon nanotubes added in asphalt at different 
percentages. The following values are the highest values observed at different percentages.

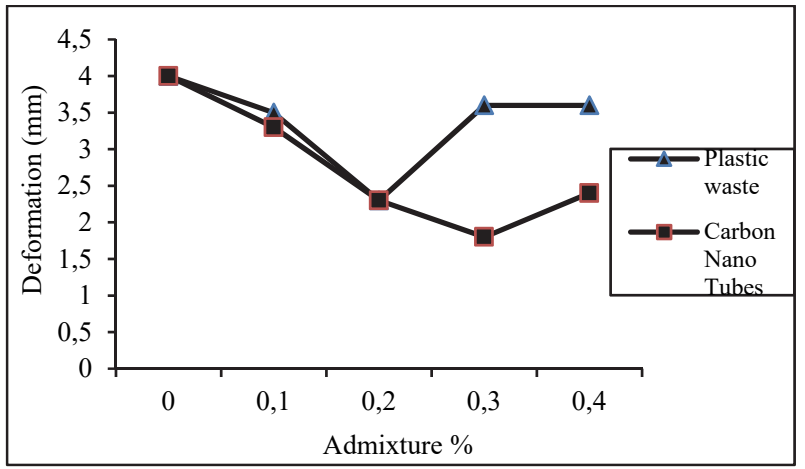

Figure 6 Rutting values of plastic waste and carbon nanotubes against its varying percentage

Fig. 6 shows that the rutting values are lower at $0.3 \%$ carbon nanotubes as compared to $0.2 \%$ plastic waste and conventional but if we compare rutting values of plastic with conventional the rutting values in case of plastic waste are much lower as compared to the conventional. This shows that the plastic is a good modifier and can be used in asphalt for decreasing the rutting. In addition, the use of plastic in asphalt for rutting purposes may decrease the cost of the project. Furthermore, the environment will be sustainable by getting rid of these non-biodegradable materials.

\section{CONCLUSIONS}

Based on the research work carried out, we can conclude that the dynamic stability is higher for carbon nanotubes and plastic modified bitumen as compared to conventional bitumen. The same is the case for the asphalt mixes. In addition, dynamic stability relatively increases with an increase in the percentage of plastic and carbon nanotubes, gradually up to $0.2 \%$ and $0.3 \%$ but on further increment in the percentage of plastic and carbon nanotubes decrease of dynamic stability occurs. The rutting values for carbon nanotubes and plastic are lower than the conventional asphalt mix. The rutting values increase with the increase of carbon nanotubes and plastic percentage but decrease when the percentage is higher than $0.3 \%$.

\section{Acknowledgments}

I would like to express my special thanks of gratitude to my supervisor Dr. Inam Ullah Khan and my Co Supervisor Dr. Malik Muneeb Abid and my friends who worked with me in this research.

\section{REFERENCES}

[1] Solanki, P. \& Zaman, M. (2017). Design of semi-rigid type of flexible pavements. International Journal of Pavement Research and Technology, 10(2), 99-111. https://doi.org/10.1016/j.ijprt.2016.10.004

[2] Pérez-Acebo, H., Mindra, N., Railean, A., \& Rojí, E. (2019). Rigid pavement performance models by means of Markov Chains with half-year step time. International Journal of Pavement Engineering, 20(7), 830-843. https://doi.org/10.1080/10298436.2017.1353390
[3] Bahia, H. U., Hislop, W. P., Zhai, H., \& Rangel, A. (1998). Classification of asphalt binders into simple and complex binders. Journal of the Association of Asphalt Paving Technologists, 67.

[4] Smagulova, N., Kairbekov, Z., Ermek, A., \& Yermoldina, E. (2012). Production of bitumens from coal sources modified by elementary sulfur. Advanced Materials Research, 535, 1815-1818. https://doi.org/10.4028/www.scientific.net/AMR.535-537.1815

[5] Masson, J. F. (2008). Brief review of the chemistry of polyphosphoric acid (PPA) and bitumen. Energy \& Fuels, 22(4), 2637-2640. https://doi.org/10.1021/ef800120x

[6] Senior-Arrieta, V., \& Córdoba-Maquilón, J. E. (2017). Mechanical characterization of porous asphalt mixes modified with fatty acid amides-FAA. Ingeniería $e$ Investigación, 37(1), 43-48. https://doi.org/10.15446/ing.investig.v37n1.57158

[7] Navarro, F. J., Partal, P., Martınez-Boza, F., \& Gallegos, C. (2004). Thermo-rheological behaviour and storage stability of ground tire rubber-modified bitumens. Fuel, 83(14-15), 2041-2049. https://doi.org/10.1016/j.fuel.2004.04.003

[8] Bai, M. (2017). Investigation of low-temperature properties of recycling of aged SBS modified asphalt binder. Construction and Building Materials, 150, 766-773. https://doi.org/10.1016/j.conbuildmat.2017.05.206

[9] Lu, X. \& Isacsson, U. (2000). Modification of road bitumens with thermoplastic polymers. Polymer testing, 20(1), 77-86. https://doi.org/10.1016/S0142-9418(00)00004-0

[10] Sengoz, B. \& Isikyakar, G. (2008). Analysis of styrenebutadiene-styrene polymer modified bitumen using fluorescent microscopy and conventional test methods. Journal of Hazardous Materials, 150(2), 424-432. https://doi.org/10.1016/j.jhazmat.2007.04.122

[11] Valtorta, D., Poulikakos, L. D., Partl, M. N., \& Mazza, E. (2007). Rheological properties of polymer modified bitumen from long-term field tests. Fuel, 86(7-8), 938-948. https://doi.org/10.1016/.fuel.2006.09.030

[12] Moreno-Navarro, F., Sol-Sánchez, M., Jimenez del Barco, A., \& Rubio-Gámez, M. C. (2017). Analysis of the influence of binder properties on the mechanical response of bituminous mixtures. International Journal of Pavement Engineering, 18(1), 73-82. https://doi.org/10.1080/10298436.2015.1057138

[13] Wang, K., Yuan, Y., Han, S., \& Yang, Y. (2019). Application of FTIR spectroscopy with solvent-cast film and PLS regression for the quantification of SBS content in modified asphalt. International Journal of Pavement Engineering, 20(11), 1336-1341. https://doi.org/10.1080/10298436.2017.1413242

[14] Yousefi, A. A. (2003). Polyethylene dispersions in bitumen: the effects of the polymer structural parameters. Journal of applied polymer science, 90(12), 3183-3190. https://doi.org/10.1002/app.12942

[15] Pérez, I., Toledano, M., Gallego, J., \& Taibo, J. (2007). Mechanical properties of hot mix asphalt made with recycled aggregates from reclaimed construction and demolition debris. Materiales de Construcción, 57(285), 17-29. https://doi.org/10.3989/mc.2007.v57.i285.36

[16] Su, N. \& Chen, J. S. (2002). Engineering properties of asphalt concrete made with recycled glass. Resources, conservation and recycling, 35(4), 259-274. https://doi.org/10.1016/S0921-3449(02)00007-1

[17] Huang, Y., Bird, R. N., \& Heidrich, O. (2007). A review of the use of recycled solid waste materials in asphalt pavements. Resources, conservation and recycling, 52(1), 58-73. https://doi.org/10.1016/j.resconrec.2007.02.002

[18] Tabaković, A. \& Schlangen, E. (2015). Self-healing technology for asphalt pavements. Self-healing materials, 285-306. https://doi.org/10.1007/12_2015_335 
[19] Yao, H., You, Z., Li, L., Lee, C. H., Wingard, D., Yap, Y. K., Goh, S. W. et al. (2013). Rheological properties and chemical bonding of asphalt modified with nanosilica. Journal of Materials in Civil Engineering, 25(11), 16191630. https://doi.org/10.1061/(ASCE)MT.1943-5533.0000690

[20] Jahromi, S. G. (2015). Effect of carbon nanofiber on mechanical behavior of asphalt concrete. International Journal of Sustainable Construction Engineering and Technology, 6(2), 57-66.

[21] Santagata, E., Baglieri, O., Tsantilis, L., \& Dalmazzo, D. (2012). Rheological characterization of bituminous binders modified with carbon nanotubes. Procedia-Social and Behavioral Sciences, 53, 546-555. https://doi.org/10.1016/j.sbspro.2012.09.905

[22] Putman, B. J. \& Amirkhanian, S. N. (2004). Utilization of waste fibers in stone matrix asphalt mixtures. Resources, conservation and recycling, 42(3), 265-274. https://doi.org/10.1016/j.resconrec.2004.04.005

[23] Khattak, M. J., Khattab, A., Rizvi, H. R., \& Zhang, P. (2012). The impact of carbon nano-fiber modification on asphalt binder rheology. Construction and Building Materials, 30, 257-264. https://doi.org/10.1016/i.conbuildmat.2011.12.022

[24] Hussain, F., Hojjati, M., Okamoto, M., \& Gorga, R. E. (2006). Polymer-matrix nanocomposites, processing, manufacturing, and application: an overview. Journal of composite materials, 40(17), 1511-1575. https://doi.org/10.1177\%2F0021998306067321

[25] Liu, X. \& Wu, S. (2011). Study on the graphite and carbon fiber modified asphalt concrete. Construction and Building Materials, 25(4), 1807-1811. https://doi.org/10.1016/j.conbuildmat.2010.11.082

[26] Zhu, J., Birgisson, B., \& Kringos, N. (2014). Polymer modification of bitumen: Advances and challenges. European Polymer Journal, 54, 18-38. https://doi.org/10.1016/j.eurpolymj.2014.02.005

[27] Tan, S. A., Fwa, T. F., \& Low, B. H. (1992). Laboratory wheel tracking apparatus for bituminous pavement studies. Journal of testing and evaluation, 20(6), 470-474. https://doi.org/10.1520/JTE11942J

[28] Moghadas Nejad, F., Azarhoosh, A., \& Hamedi, G. H. (2014). Effect of high density polyethylene on the fatigue and rutting performance of hot mix asphalt - a laboratory study. Road Materials and Pavement Design, 15(3), 746756. https://doi.org/10.1080/14680629.2013.876443

[29] Rokade, S. (2012). Use of waste plastic and waste rubber tyres in flexible highway pavements. International conference on future environment and energy, IPCBEE, 28.

[30] Vasudevan, R., Sekar, A. R. C., Sundarakannan, B., \& Velkennedy, R. (2012). A technique to dispose waste plastics in an ecofriendly way - Application in construction of flexible pavements. Construction and Building Materials, 28(1), 311-320. https://doi.org/10.1016/j.conbuildmat.2011.08.031

[31] Arabani, M. \& Faramarzi, M. (2015). Characterization of CNTs-modified HMA's mechanical properties. Construction and Building Materials, 83, 207-215. https://doi.org/10.1016/i.conbuildmat.2015.03.035

[32] Agzenai, Y., Pozuelo, J., Sanz, J., Perez, I., \& Baselga, J. (2015). Advanced self-healing asphalt composites in the pavement performance field: mechanisms at the nano level and new repairing methodologies. Recent patents on nanotechnology, 9(1), 43-50. https://doi.org/10.2174/1872208309666141205125017

[33] Faramarzi, M., Arabani, M., Haghi, A. K., \& Mottaghitalab, V. (2015). Carbon Nanotubes-modified Asphalt Binder: Preparation and Characterization. International Journal of Pavement Research \& Technology, 8(1). https://doi.org/10.6135/ijprt.org.tw/2015.8(1).29

[34] Huang, Y., Bird, R. N., \& Heidrich, O. (2007). A review of the use of recycled solid waste materials in asphalt pavements. Resources, conservation and recycling, 52(1), 58-73. https://doi.org/10.1016/j.resconrec.2007.02.002

[35] Yildirim, Y. (2007). Polymer modified asphalt binders. Construction and Building Materials, 21(1), 66-72. https://doi.org/10.1016/j.conbuildmat.2005.07.007

\section{Contact information:}

\section{Aamir Ayaz KHAN}

Civil Engineering Department,

Millitary College of Engineering (MCE-NUST), Pakistan

E-mail: khan.aamir7806@gmail.com

\section{Inam Ullah KHAN}

Department of Civil Engineering,

National University of science and technology, Islamabad

E-mail: inam_bunny@hotmail.com

\section{Malik Muneeb ABID}

(Corresponding author)

Department of Civil Engineering,

College of Engineering and Technolgy,

University of Sargodha

E-mail: muneeb.abid@uos.edu.pk

\section{Muhammad NOMAN}

Department of Civil Engineering,

Faculty of Engineering \& Technology,

International Islamic University, Islamabad

E-mail: muhammad.noman@iiu.edu.pk

\section{Umair Ayaz KHAN}

Department of Civil Engineering,

University of Engineering and Technology, Peshawar

E-mail: awaiszahidciit@gmail.com

\section{Muhammad BILAL}

Department of Civil Engineering

Millitary College of Engineering (MCE-NUST), Pakistan

E-mail:mbilalnust@gmail.com 